
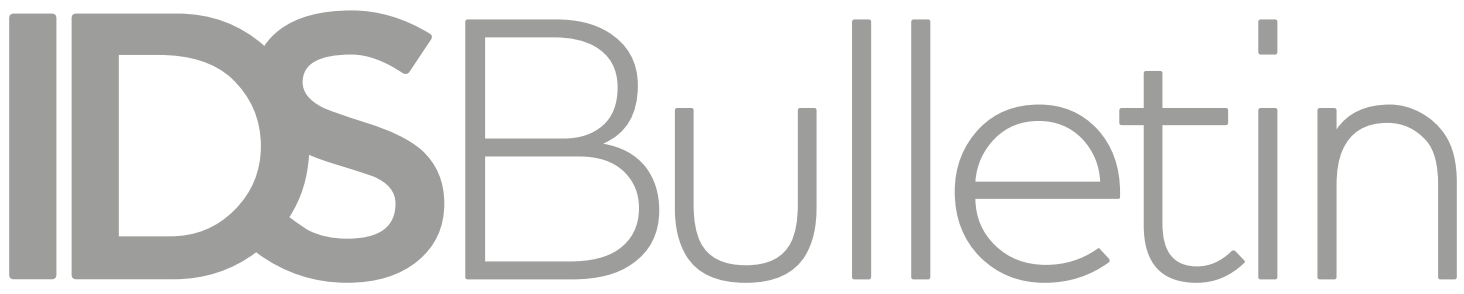

Transforming Development Knowledge

ARCHIVE COLLECTION

Volume 49 | Number 1A | April 2018

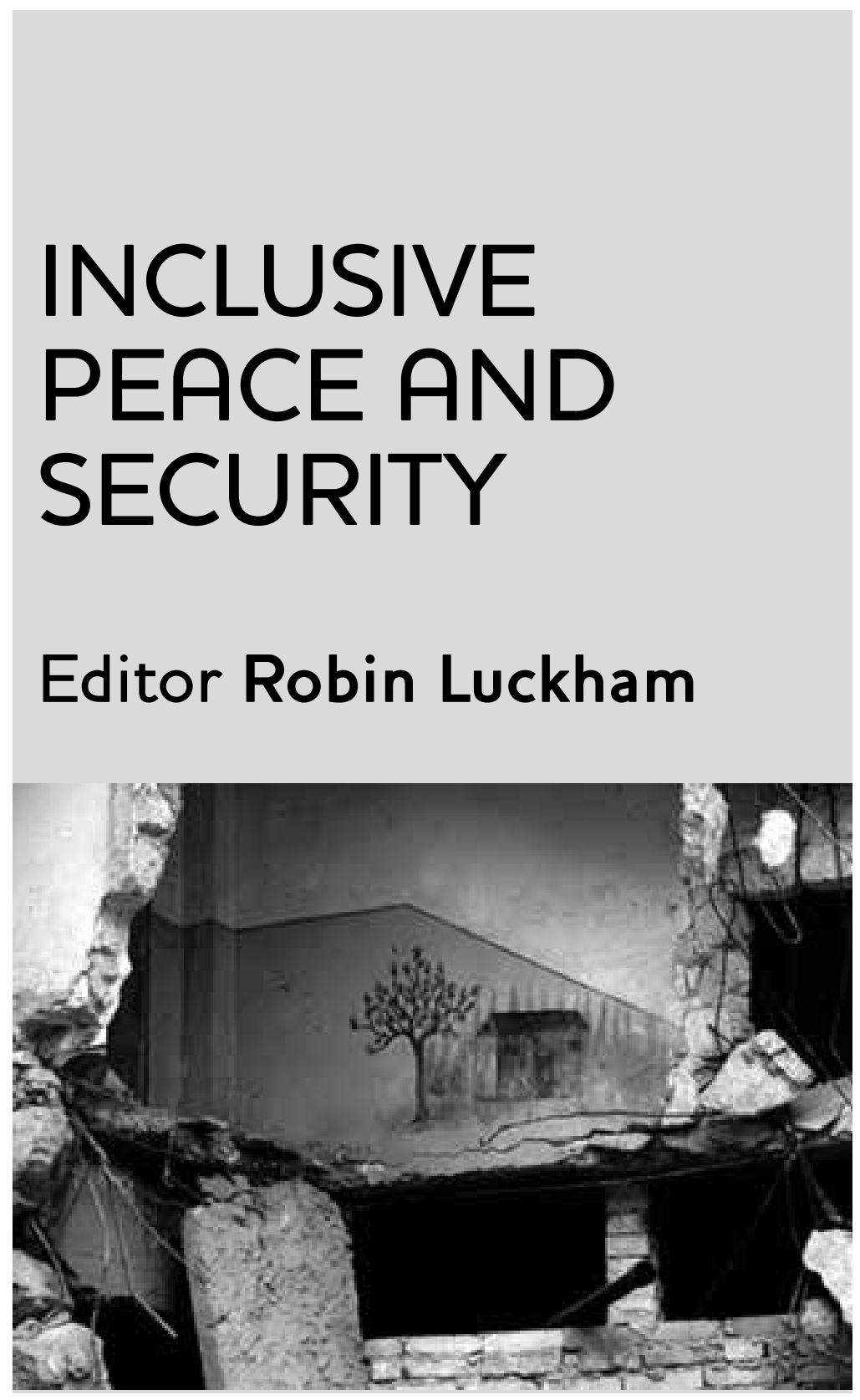




\section{Contents}

From Disarmament and Development to Inclusive Peace and Security:

Four Decades of IDS Research

Robin Luckham

Article first published April 2018, IDSB49.1A

Peace and Development

Willy Brandt

Article first published October 1985, IDSB16.4

Editorial: Disarmament and Development - the International Context

Robin Luckham

Article first published October 1985, IDSB16.4

Globalism Versus Villagism: Food Security and Environment at National and International Levels

Susanna Davies and Melissa Leach

Article first published July 1991, IDSB22.3

War and Famine in Africa

Alex de Waal

Article first published October 1993, IDSB24.4

Insecurity, Conflict and the New Global Disorder

Susan Willett

Article first published May 2001, IDSB32.2

Peace Through Agrarian Justice

Paul Richards and Khadija Bah

Article first published June 2005, IDSB36.2

'Security from Below' in Contexts of Chronic Violence

Alexandra Abello Colak and Jenny Pearce Article first published March 2009, IDSB40.2

Gendering the New Security Paradigm in Sri Lanka

Neloufer de Mel

Article first published March 2009, IDSB40.2

Researching the Gendered Silences of Violence in El Salvador

Mo Hume

Article first published May 2009, IDSB40.3

Quantitative Methods in Contexts of Everyday Violence

Patricia Justino, Jennifer Leavy and Elsa Valli Article first published May 2009, IDSB40.3

\section{Crime and Social Cohesion in the Time of Crisis: Early Evidence of Wider Impacts of Food, Fuel and Financial Shocks}

Naomi Hossain

Article first published September 2009, IDSB40.5

Social Contracts, Networks and Security in Tropical Africa Conflict States:

An Overview

David K. Leonard

Article first published January 2013, IDSB44.1

This article has been reissued as part of IDS Bulletin Archive Collection Vol. 49 No. 1 A April 2018: ‘Inclusive Peace and Security’; the Introduction is also recommended reading. 


\title{
Crime and Social Cohesion in the Time of Crisis: Early Evidence of Wider Impacts of Food, Fuel and Financial Shocks
}

\author{
Naomi Hossain*
}

\begin{abstract}
Economic crises have a series of impacts on society and security, depending on their severity, and on people's capacities to cope with and adapt to stresses on livelihoods and community relations. This article highlights findings about how local-level security and social relations have been affected by the global food, fuel and financial shocks since 2008. Based on original research from a qualitative and participatory study in Bangladesh, Indonesia, Jamaica, Kenya and Zambia in early 2009, it discusses local perspectives on how crime and social cohesion have been affected across ten case study communities involved in the study. It identifies a number of common directions of change categorised here as broadly 'crime'. It is suggested that crime and social cohesion are important potential indicators of the impact of economic crisis. The article concludes with a discussion of the poverty, political and governance implications of crisis-driven impacts on crime and social cohesion.
\end{abstract}

\section{Introduction: untangling the impacts of complex compound crises}

A widely learned lesson from history is that economic crises can have seismic effects on society and security. This article looks at some of these from the perspectives of rural and urban people living in Bangladesh, Indonesia, Jamaica, Kenya and Zambia. It is based on original research into the global economic crises, including the food and fuel crises that dominated 2008, and it focuses on the crime and social cohesion impacts. These include that livelihood adaptation strategies have left people at or over the edge of legality, and concerns about youth criminalisation and the provision of policing and security. Inter-group and community relations show signs of strain after economic shocks, particularly the food price crisis; there are also signs that community support mechanisms, including local charity, have faltered under this strain. The article concludes with some discussion about the importance of monitoring the wider social impacts of crisis: the insights this will provide should not only aid understanding of how crisis is being experienced and mediated, but also offer potential insights into supportive interventions. Crucially, both crime and social cohesion impacts have immediate consequences for people's wellbeing, as well as the more enduring potential consequences for economic development, governance conditions and politics.

\subsection{Which crisis? Experiments with people-centred monitoring in five countries}

The research on which this article is based was a pilot study commissioned by the UK Department for International Development which aimed to:

(a) provide 'real-time' data on the human impacts of the food, fuel and financial crises and

(b) test an approach to participatory and qualitative monitoring. Details on country and site selection, as well as more detail on the research findings, can be obtained in Hossain et al. (2009). The research was undertaken in rural and urban communities, one each in Bangladesh, Indonesia, Jamaica, Kenya and Zambia, during February 2009. Methods included a mix of 
qualitative and participatory tools and techniques such as focus group discussions and case study research; in most cases, the researchers had prior relationships with the community through earlier research. The social impacts of the crisis were a specific area of focus.

The value of the research was chiefly that it demonstrated the scope for rapid snapshots of the experience of economic crisis that would go beyond and humanise the macroeconomic statistics that dominate measurement of impact. In addition, as this article shows, it enables an exploration of the non-economic dimensions of economic crisis that quantitative monitoring methods are unlikely to capture. It also highlighted the complex nature of the multiple crises being experienced. Particularly crucial was that the exploration of experiences of crisis shed light on how the impacts of the food and fuel crises were undermining capacities to cope with the global financial crisis, which in February 2009 was still only beginning to be felt in some poor developing country communities.

The limitations of the approach are primarily of scale, and include the constraints to generalisation due to the qualitative, community-based approach. The findings are illustrative rather than representative. In recognition of these important limitations, the present article does not claim to represent conditions in all contexts, but to highlight processes and routes through which crime and social cohesion have been affected in the ten communities in the study, and to indicate broader lessons about the impact of economic crisis on crime and social cohesion in developing country contexts.

A key finding of the research was that even as the global financial crisis was beginning to strike developing countries, many communities were reeling from the effects of the food and fuel crises. Food prices had not come down everywhere, nor by enough to bring them down to pre-2008 levels. The research found that global crises were being compounded locally by adverse climate conditions locally (drought in Kenya and Jamaica, localised flooding in Indonesia, cyclone and floods in Bangladesh, heavy rains in Zambia) and difficult political transitions (post-election violence in Kenya, a caretaker interregnum in Bangladesh); these additional factors were contributing to uncertainty around agricultural production and local economic decline. Compound, complex crises were found to be interacting with each other, making it difficult to disentangle their impacts on people's lives.

These local accounts of how the crises were being experienced offered insights into how the food, fuel and financial crises were unfolding in poor developing countries. The situation was different everywhere, but everywhere were signs of strain. Many people were trying hard to adapt their livelihoods. There was support from within communities, as well as some valued government and faith-based support. But many people were reporting not being able to make ends meet: managing food, health and educational needs was proving to be a struggle, and not only for the very poorest; many middle class people were also reported to be finding the high prices difficult to cope with. For some, particularly children, there were impacts that looked set to be irreversible, because they were dropping out of school to earn or because their parents could not afford fees, books, or breakfast. As this article discusses in more detail, the ties that bind communities together were showing signs of unravelling, as people were getting together to save or celebrate less than they used to. While there was evidence of neighbourly support, some believed this was declining. In all five countries, people believe crime rates have risen. From the worst-hit communities were reports that children and the elderly were being abandoned by people no longer able to cope. In terms of social protection, people reported that some government programmes were working well. The most widely heard complaints included that these covered too few people with too little support to make a difference. Other schemes were not reaching the poorest. And much assistance - including from religious institutions and NGOs - was considered to be unpredictable or even to be declining.

\section{Crime in a time of crisis \\ 2.1 Livelihoods at the edge of legality}

Reports that the economic shock of high food prices was prompting diversification into new economic activities were common in all the communities. In many instances, this involved a shift into informalisation: traders and food sellers reported shifting into unbranded or repackaged goods. This suggests a rise in 
unregulated sales of food items, with considerable scope for adulteration and contamination. Poor women in the community in Dhaka, Bangladesh, had carved out a niche in sales of rejected vegetables as prices rose and remained high throughout 2008; this included selling food items that had been rejected as unfit for sale, and, reportedly, of items stolen from wholesale deliveries to markets. In the Kingston communities in Jamaica, people were reportedly finding 'novel ways of hustling': one strategy reported was that of 'goose men' who accept sales commissions and then over-charge for the product, to increase their commission rates.

Men in the rural Kalimantan village in Indonesia, had responded to the downturn in the rubber trade on which their livelihoods had depended by travelling to another island to engage in illegal gold mining. Having borrowed funds to finance the travel and mining equipment costs, they encountered official raids and some were ultimately driven back to Kalimantan, having lost more than they had earned by mining gold. By contrast, in rural Bangladesh, cross-border smuggling of fertiliser became highly lucrative at the height of the fuel prices, when fertiliser costs peaked. Landowners in the rural community in Naogaon complained that smuggling had become so common a livelihood strategy there that agricultural wage labour rates had been driven up, in response to the labour shortage that resulted.

In Dhaka, Bangladesh, the unregulated end of the garments industry was reporting to be thriving since the start of the global financial crisis in the final quarter of 2008. This was seen in the good trade among many small subcontractor factories, whom garments workers claimed were as, if not more numerous than before, and hiring as many, if not more workers. These smaller factory units are mainly sweatshops that do not comply with labour and social standards of production; workers complained that these were factories in which managers 'misbehave with workers and beat and abuse them ... They will hire you instantly. But there is no job security there. After ten days they may fire you'. In the peri-urban Jakarta community, the global downturn was also bringing regulatory weaknesses in the protection of workers' rights to the fore; there were reports that workers who had been laid off were experiencing difficulties claiming their entitlements from the labour outsourcing companies through whom they had been contracted.

In many communities, people felt that petty theft was on the rise. In the Jakarta community, motorcycle and mobile phone theft was reported to have risen. This was the only community in which it was possible to triangulate these findings with reference to official crime statistics. There, local police confirmed that there had been a rise in reported crime in the previous three months (up to February 2009). While there was a seasonal element to this crime rates often rise in the period preceding the major Eid festival - the police noted that the rise was over and above seasonal increases. This suggested that economic crisis was driving rises in rates of reported crime.

\subsection{Substance abuse and antisocial behaviour}

Concern was expressed in all the countries about criminalisation and/or substance abuse among youth, directly attributed to the pressures of the crisis. In Kenya this was associated with concerns about how unmarried youth were being excluded from relief. Raised levels of drug abuse were reported in Bangladesh, Jamaica, Zambia, and Kenya, and rising alcohol abuse was reported in Zambia, Kenya and Indonesia. In Zambia, young focus group participants chewed khat throughout the session. A man in Nairobi said that:

\section{A man in hunger cannot afford leisure. Even if one drinks beer, it is not for leisure as before, but just to kill the stress.}

Other focus group participants in Nairobi said that the lethal local brew 'kill-me-quick' was replacing the beer that people used to drink for leisure. While in some contexts this was seen as merely an antisocial or wasteful way of coping with the stress and frustration of coping with crisis, in Kenya and Jamaica there were concerns that this was connected to a growing involvement in the drugs trade among young people in these communities.

Children and youth becoming involved in criminal economic activity were also reported. Again in Nairobi, a headteacher told the following story of criminalisation among schoolchildren: 
A copper bell belonging to our school was stolen by one of the students and sold to a scrap metal dealer at an industrial area at a cost of KSh20. The bell was very valuable to the school since it was bought when the school was first opened. We pursued the issue with the chief and after investigations we learnt that the boy had sold it to a middleman who then sold it off to the dealer. By the time we got to the dealer, the bell had already been smelted. I received threats from the middleman that I would be raped should I pursue the issue further.

Children in Nairobi were also reported to be carrying criminals' guns for a fee of KSh25.

Girls and young women were said to be increasingly entering into sex work in Kenya and Zambia. In Lusaka, youths reported a rising number of girls and young women entering sex work as one of the most significant problems facing their community, caused by poverty and unemployment, family problems and low income, and the pressure 'to look good'. Among the effects they detailed included HIV/AIDS/STIs, children being born out of marriage, and school dropout. In Nairobi, youth had also witnessed a rise in sex work, involving girls as young as 14, as well as boys. Teachers in Nairobi attributed the rising number of schoolgirl pregnancies to hunger, as girls were believed to have been exchanging sex for food and snacks. In the research community, there had been 13 pregnancies in primary schools in 2008, a figure which teachers felt constituted a rising trend.

\subsection{Policing and security}

There were some indications that the provision of policing and security had also been affected by economic crises in these communities. The impacts of crisis on the state of policing were traced most directly in Kingston, where people had the following to say:

More police are on the road but the police are also hustling.

I asked one policeman for money and he said 'when him done run the road' [taken bribes from drivers]. More police hustling since the crisis. Dem a di biggest hustlers, tief and extortionists. Nuff a dem a criminal who get license to become police. They wear knapsack and go around collecting.

Over the last year, problems with police have become worse.
In the Kingston communities there was no strong sense that that crime rates were rising, even though people were generally agreed to be 'hustling' and 'going on the juggle' - finding ways of earning a living that were not necessarily within the law. It is possible that this is because rises in criminal activity are not being felt locally but involve acts perpetrated in other locations. Control by powerful 'dons' in these Kingston communities had maintained local order according to local rules without any inter-group violence in the previous five months:

Under community rules and regulations, there is to be no violence against women, no [thieving], no raping, no disrespect to elders, no telling tales to Babylon, no homosexuality (though we have it here a lot; all bad man too). If you are found in the act, you get flogged. People use sticks and big boots. If two women fight, they get beaten too.

In the Nairobi community, local security was also being provided by what appeared to be criminal gangs. Business owners reported paying a mandatory daily fee of KSh20 to a group called the 'Maasai' to ensure the security of their business. That this group was reported to have prevailed in recent clashes with the feared mungiki militia group ${ }^{1}$ gives a sense of the degree of violence and control exerted on the local community under study.

The burden of coping with insecurity and ineffective law and order in poor communities may be exacerbated by economic crisis, as they add to financial strains that for some households are already unbearable. This was brought home in the case of one Dhaka household which was struggling to continue fighting a case against their former landlord who had raped their, then, 13-year-old daughter the year previously. Her father and uncle had raised the Tk100,000 (US\$1,450 at May 2009 rates) so far needed to fight the legal battle, but in so doing left the family destitute. They had moved to the slum in which they were interviewed to cut expenses, the girl had been removed from school to try to contribute to the family income by working, and her mother was now working in a garment factory; meanwhile her grandmother had returned to the village to try to raise the money to keep her younger brother in school. But the food price crisis had added to an already difficult financial and law and order situation, and the future of the legal case was uncertain. 


\section{Social cohesion}

\subsection{Inter-group and community relations}

There were incipient signs of social tension between social groups, most notably in the Nairobi community. The most tangible signs of growing tensions emerged in relation to majority Christian views on a feeding programme for practising Muslims:

Although we are suffering as youth in [the Nairobi community], and our parents and friends are struggling, the Muslims always have food. Every Friday, the mosque opposite provides food and even clothing. This support is only for Muslims. We have been to the mosque a few times dressed in buibui ${ }^{2}$ like the other Muslim women and managed to get food. It seems the people at the Mosque found [out]. We are told they cannot give food to kafirs. A few weeks back our friends, young men, were caught dressed in buibui like women; it was embarrassing, but we must survive. (FGD participant, Nairobi)

The exclusion of people of other faiths from the support provided by Muslims seemed to generate animosity and intense hostility. Some people argued that when there is support from the church or government there is no discrimination, yet Muslims were seen to be encouraging discrimination, and possibly using food to convert desperate residents to the Islamic faith. Also in Nairobi, there were accounts of young boys being sold to Asian traders for sex in exchange for food; such reports highlight how deprivation has heightened awareness of socioeconomic differences along religious or ethnic-cultural lines, creating social tensions.

In both the rural Bangladesh and the Jakarta community, there was a tendency to deny that minority social groups were disadvantaged compared with the majority. In both communities, the impression that was conveyed was one of social harmony, despite difference. This may indeed be true under non-crisis conditions, although what appears to majority and powerful groups as social harmony may also be containment of social tension or divisions. ${ }^{3}$ In both those communities, there were minority groups that were disadvantaged with respect to official social protection schemes. In rural Bangladesh, the indigenous Shaotal population is typically excluded from government programmes, the benefits of which are in the hands of local government representatives who seek to maximise political capital from their distribution. Church- and Christian faith-based organisations were known to provide some social services to this group, however. And the Shaotal population has a political history of mobilisation around their rights in this part of Bangladesh. In the Jakarta community of Gandasari, migrant export sector workers were generally excluded from the rice for the poor and cash transfer schemes from which some longer-term residents benefit. While this was not a community featuring the exclusion of all migrants - other non-natives had received considerable help from local officials and community leaders, including the right to live on public land - there was a distinct sense of separation between the temporary residents and the more permanent inhabitants. In both rural Bangladesh and Jakarta, there was ample scope for social tensions to arise around the distribution of resources for coping with crisis.

In Bangladesh, Indonesia and Jamaica, there were also signs that social practices that had previously cemented the social capital between groups were declining. The decline of the arisan or rotating savings scheme in the rural Indonesian site (see below) also affected attendance at the yasinan or weekly group recitation from the Koran, which had been conducted at the same time, and which was an important regular social event. Many people said they no longer attended. To date, however, community members noted that there had not been any conflict among the participants, and there were other signs that a sense of solidarity within the community was strong; this social harmony was attributed to a shared reliance on rubber farming, and fairly strong adherence to common religious practice. However, as the impacts of the global financial crisis in the form of low rubber prices persisted into the fifth month, people were concerned that the community's harmony, mutual understanding and safety would begin to be affected, and that practices of giving credit and helping each other were at risk as the financial situation continued to worsen.

Changes in social participation were not noted in the Jakarta site; there, people said they were still managing to contribute to, for example, funeral costs, borrowing from family members if necessary, in order to meet this important social 
obligation. But in rural Bangladesh, people noted a decrease in the number and scale of major social events such as weddings or milads (prayer and sermon sessions to mark anniversaries or important events). There were fewer such big occasions now held, fewer people were invited, and the food was less lavish when they did occur. Together with the reported decline in private and informal charity in some contexts, these changes in social behaviour signal a growing inability to finance the rituals and practices that bind societies together.

\subsection{Credit}

Customary savings and credit groups appear to have been most important in the rural Indonesian and both the rural and the urban Jamaican communities. No such groups were mentioned as prominent potential or actual sources of support in either Bangladesh or Zambia. However, in both rural Indonesia and Jamaica, these customary modes of rotating savings and credit appear to have suffered during the current crisis. The Jamaican practice of 'throwing partners' involves a group of likeminded community members who agree to collectively save on a regular basis, with an agreed banker and period of time between 'draws'. In Kingston, some investors in a financial services company that had crashed in early 2008 were reported to have invested their partner money in the company. Other views were that the practice was struggling during the downturn:

We used to survive by throwing partners. Now, we don't have the income to save to throw partners. You see partner a throw, you have to know where the money is coming from or else you may start the partner and can't maintain it.

\section{The partner thing don't work well like last time. Without jobs, it's impossible.}

The view was similar on the other side of the world in rural Banjar, Indonesia, where arisan had to date been the main source of capital in the community. Arisan are customary groups that bring together between tens and hundreds of community members, who agree to save a fixed amount, usually starting at around Rp5,000 each, which are raffled off weekly. Most community members are members of an arisan. The weekly arisan meeting has to date been a major event in this community, and also involves a yasinan or
Koran recitation. However, recent changes include the postponement and even the disbanding of some arisan. In one case, a group that had only conducted the raffle twice was terminated, and the winners of the arisan funds were asked to return the funds. Others have increased the timetable to once every two or four months, which seems to be more manageable for people during a period of financial strain.

\subsection{Charity}

Informal sources of support, in particular loans and gifts from neighbours, relatives and local shops, stalls and food vendors were relied on by many at the height of the food crisis. Migrant remittances may also fall into this category of charitable support, particularly where payments are occasional support to poor relatives in times of household crises such as illness or death, rather than regular payments. However, there were some findings that indicated that informal private charity had been hit hard by the crisis. The experiences of women earning a living as beggars in rural Bangladesh were indicative; they reported the following changes since the crisis: (a) a halving of the amounts of rice they used to earn regularly by begging; ${ }^{4}$ (b) a decline in other charitable gifts (clothes, cash);

(c) competition with other poor and even lower middle class people over wild foods gleaned from public and private lands; and, (d) a matter which greatly offended these women's sense of personal dignity, a rise in aggressive and rude responses to requests for alms. Other people reported that it was less possible than before to depend on neighbours and relatives for support, because all were suffering from the food and fuel crisis. One reason that informal support may have declined is that food and fuel prices appear to have hit middle-class or relatively affluent groups in these communities fairly hard.

Informal private charity may have been hit particularly hard because many middle class people are in formal sector occupations where cash incomes are relatively fixed over the short to medium term; by contrast, informal sector traders, people involved in the extra-legal economy, and even manual wage labourers in some sectors have seen their nominal incomes rise, even if in real terms they remain absolutely worse off, their decline in purchasing power has been somewhat less precipitous. Informal charity appears to be highly elastic, and quick to decline 
when middle class incomes drop. In Bangladesh women engaged in begging reported that wealthy people had brushed off their requests for assistance with reference to government programmes to which they are, at least in theory, entitled.

The impacts of crisis on charitable giving were not all negative, however. Near the Dhaka community, a charitable feeding programme at the tomb of a Sufi saint was reported by the manager to have received more donations at the time when food prices were at their peak, when they were feeding some 550 people daily. Most charitable donors to the tomb are themselves poor, and the manager speculated that it is because political and economic crises make people feel more vulnerable that they depend more on extra-mundane (spiritual and religious) means to help them through crises; this is why donations rise during crises. One pilgrim the researchers met during the research had brought a goat as an offering. He was a poor man, like most of the other two million pilgrims each year. It had taken him six months to save the money to pay for the goat, and he had brought it because he had vowed to sacrifice a goat in return for his daughter's recovery from her illness. Donations from poor people like this pilgrim were reported to have kept the food service and other charity activities of the tomb going during the crisis, and donations had almost doubled over the period 2005-6 to 2007-8.

\section{Conclusions: why crime and social cohesion \\ matter for development}

The research discussed above does not claim to be representative, even of the countries in which it was conducted. It may not be possible to generalise about the likelihood that economic crisis will lead to rising crime and declining social cohesion in poor communities. However, the evidence presented here provides credible illustrations of the routes through which serious shocks to food security, as occurred throughout the world in 2008 and continue to occur well into 2009, can result in informalisation and more seriously, a criminalisation of livelihoods, as well as undermine the bases and forms of social connectedness in communities.

There are at least three reasons why the impacts of economic shock on crime and social cohesion levels matter centrally to crisis coping and development prospects in the recovery period. The first is that levels of crime and social cohesion are likely to be of central significance because of their immediate or short-term impacts on people's wellbeing. Participatory approaches to understanding the experience of poverty such as the Voices of the Poor study have consistently identified crime and violence as prominent features of the experience of poverty in its more multi-dimensional senses, or illbeing. ${ }^{5}$ Similarly, it is now widely recognised that livelihood strategies for adapting to and coping with food insecurity crises depend more on communitybased support than is typically documented. ${ }^{6}$

A second reason these broader social impacts matter is their potential economic and poverty impacts in the medium term. There are good reasons to believe that social fragmentation during protracted economic downturn will have enduring effects on societal responsibilities for children, the elderly and the very poor. In the current crisis, there were signs from Bangladesh that the local elites who bear customary responsibility for supporting the very poor were abandoning those responsibilities, and redefining the role of state and NGO programmes to replace them in those roles. The sense of uncertainty bred by rising crime is also likely to have enduring medium-term impacts. In one particularly telling instance, a farmer in the rural Kenyan community in the study explained his hesitation about planting food crops, despite the high prices he could expect to earn from them:

\section{I have been growing maize, beans and other crops ... I have been sacrificing a lot in terms of minimising expenditure in order to buy fuel only to find my crop stolen from the shamba. This kind of theft was unheard of in the period before 2007. It has been brought about by lack of food since those that steal do it to feed themselves and their families and not for commercial purposes.}

A third reason crime and social cohesion impacts are likely to be of more enduring significance in the crisis recovery period is the potential longerterm impacts on politics and governance conditions. While reported rising crime rates in these communities are an insecurity phenomena of a significantly lower intensity than found in conditions of conflict and civil war, there are parallels with the impact of economic shock on the shift into semi-legal and criminal livelihood 
activities that are worth attending to. In her analysis of the micro-level factors that shape the relationship between poverty and violent conflict, Justino points out that relatively little is known about how 'micro-level economic factors and decisions influence the start of violent conflicts', and that strategies for adaptation for survival may include 'adopt [ing] forms of livelihoods that may lead to severe poverty traps but avoid famine ... or may lead to a life of crime and violence (or both) (Justino 2009: 3-4).

With Justino's reminder that we are yet to fully understand the 'micro-level economic factors and decisions' that influence the start of violent conflicts, it is worth recalling the political effects of the current crises so far. The current crisis (including global food price inflation) has already witnessed a considerable amount of political turmoil. While no source for the muchcited figure that 30 countries had experienced demonstrations or what are loosely called 'foot riots' since 2008 could be found, a five-minute internet search found credible references to such protests in Bangladesh, Burkina Faso,

Cameroon, Côte d'Ivoire, Egypt, Ethiopia, Guinea, Haiti, India, Indonesia, Mauritania, Madagascar, Mexico, Morocco, Mozambique, Pakistan, Philippines, Senegal, Somalia, Uzbekistan, and Yemen. Two West African countries and Haiti saw governments topple as a result of the food and/or financial crises in the last year. In Bangladesh, the siege of barracks and gruesome massacre of army officers by their subordinates in February 2009 was initially explained by frustrations around inadequate pay in a time of food inflation.

There is little interest in or understanding of these protests. In the current crisis, food riots seem to be seen as an automatic, almost physiological response to acute food insecurity. See this description of financial crisis 'contagion' by a leading New York University economic forecaster in the blogosphere:
If cargo trade stops, the wheat doesn't get exported. If the wheat doesn't get exported, the mill has nothing to grind into flour. If there is no flour, the bakeries and food processors can't produce bread and pasta and other foods. If there are no foods shipped from the bakeries and factories, there are no foods in the shops. If there are no foods in the shops, people go hungry. If people go hungry their children go hungry. When children go hungry, people riot and governments fall. (Roubini 2008)

But food riots are a political phenomenon, a barometer of political opinion and capacity to mobilise. While elite observers often assume that mass protests of this kind are stirred up by outside rabble-rousers with their own political agenda, there are better reasons to believe that they emerge out of or are informed by a shared political ideology about the responsibilities of government or the authorities during episodes of food crisis.

While it involves a considerable stretch to detect political and governance impacts of this higher order in this local evidence of rising crime and declining social cohesion, it is known that perceptions of public safety shape attitudes towards democracy (Fernandez and Kuenzi 2006; Pérez 2003/4). And there are reasons to believe that political trust in poor, risk-prone societies rests considerably on governmental capacities to support people during crises (Hossain 2008). In brief, faith in democratic governments can be at stake during economic crisis. Monitoring the wider social impacts of economic crisis, with a particular focus on crime and social cohesion, is thus about tracking factors that affect poor people's immediate, medium- and longer-term capacities to cope and to live well. The combination of the potential short-, medium- and long-run impacts of crime and social cohesion, for poverty and for politics, suggests these are important indicators of the development impacts of economic crisis in poor countries. 


\section{Notes}

* This article is based on research conducted by partners, the partners included: Mamunur Rashid, Bayazid Hasan, Nabil Zuberi and Sheikh Tariquzzaman of BRAC Development Institute in Bangladesh; Rizki Fillaili, Widjajanti I. Suharyo, Bambang Sulaksono, Hastuti, Herry Widjanarko, Sri Budiyati, Syaikhu Usman, Nur Aini, and Faisal Fuad Seiff of the Social Monitoring and Early Response Unit (SMERU) in Indonesia, Joy Moncrieffe (IDS), Paulette Griffiths-Jude and Nellie Richards in Jamaica, Grace Nyonyintono Lubaale of Mpereeza Associates with Peter Otienoh Orwa, Elizabeth Kariuki and Maurice Owino Ligulu in Kenya, and Mwila Mulumbi of Civil Society for Poverty Reduction, Lusaka and Wala Mubitana in Zambia.

1 For more details on the mungiki, see The Economist, 'Next Machetes, Then Machineguns?' 12 March 2009.

2 A garment that covers the head and body worn by Muslim women; a local variant of the burkah.

3 During focus groups with women in the Jakarta community the researchers noted a visible tendency for the discussions to be dominated by the permanent villagers; migrant worker women were notably more hesitant and reluctant to speak. Views on social harmony within the

\section{References}

Adams, A. (1993) 'Food Insecurity in Mali: Exploring the Role of the Moral Economy', IDS Bulletin 24.4: 41-51

Brock, K. (1999) "“It's Not Only Wealth That Matters - It's Peace of Mind Too": A Review of Participatory Work on Poverty and Illbeing', background paper prepared for the World Development Report 2000/1, Brighton: IDS

Corbett, J.E.M. (1988) 'Famine and Household Coping Strategies', World Development 16.9: 1009-12

Davies, S. and Hossain, N. (1997) Livelihood Adaptation, Public Action and Givil Society: A Review of the Literature, IDS Working Paper 57, Brighton: IDS

Fernandez, K.E. and Kuenzi, M. (2006) Crime and Support for Democracy: Revisiting Modernization Theory, Working Paper 64, Kampala: Afrobarometer Hossain, N. (2008) Who Trusts Government? Understanding Political Trust Among the Poor in Bangladesh, Asia Research Institute Working Paper Series 103, Singapore: National University of Singapore community, could easily reflect the relative power of permanent local residents, many of whom are landlords of migrant workers.

4 In Bangladesh and across parts of South Asia, begging does not generally attract the level or type of stigma it does in contemporary Western societies; for many, giving to beggars can be a spiritual act which brings religious blessings. Widows and people with disabilities may be able to survive on the income from begging, as had been the case for the group of beggar women involved in this research.

5 In her review of participatory explorations of poverty and illbeing, Brock (1999) found that crime and violence and fear of crime and violence were significant sources of illbeing for poor people. The participatory 'Consultations with the Poor' exercise conducted for the World Development Report 2000/1 also identified crime as a major source of illbeing for the poor. However, the final Report contains relatively little discussion of this point. One advisor to the participatory research process, Robert Chambers, noted that while the police had emerged as an important institution affecting poor people's wellbeing, this point had been excluded from the final report.

6 See Adams (1993); Corbett (1988); Davies and Hossain (1997).

Hossain, N. et al. (2009) 'Accounts of Crisis: Poor People's Experiences of the Food, Fuel and Financial Crises in Five Countries', report on a pilot study in Bangladesh, Indonesia, Jamaica, Kenya and Zambia, January-March 2009, mimeo, Brighton: Institute of Development Studies, UK, www.ids.ac.uk/go/ idsproject/voices-on-three-crises-the-impactsof-the-financial-food-and-fuel-crises-ondeveloping-countries (accessed 3 July 2009)

Justino, P. (2009) 'Poverty and Violent Conflict: A Micro-Level Perspective on the Causes and Duration of Warfare', Journal of Peace Research 46.3: May

Pérez, O.J. (2003/4) 'Democratic Legitimacy and Public Insecurity: Crime and Democracy in El Salvador and Guatemala', Political Science Quarterly 118.4, winter: 627-44

Roubini, N. (2008) Systemic Risk Contagion and Trade Finance: Back to the Bad Old days, blog, www.rgemonitor.com/financemarkets-monitor/ 254399/systemic_risk_contagion_and_trade_ finance_-_back_to_the_bad_old_days) (accessed 3 July 2009) 